\title{
Crítica de arte para a expansão dos sentidos
}

\author{
Rízzia Rocha'
}

Resumo: O presente artigo propõe examinar as mudanças na crítica de arte responsáveis por sua crise como atividade fundamentada no ajuizamento, na contextualização e teorização das produções artísticas. A partir dessa análise, o conceito de crítica poética é explorado como uma das atuações da crítica na produção artística contemporânea.

Palavras-chave: Crítica de arte. Crise. Transformações da crítica. Arte contemporânea.

\section{Art criticism to the expansion of the senses}

\begin{abstract}
The objective of this paper is to examine the changes in art criticism responsible for its crisis as an activity based on the judgement, contextualization and theorization of artworks. Based on this analysis, the concept of poetic criticism is explored as one of the actions of criticism in contemporary artistic production.
\end{abstract}

Keywords: Art criticism. Crisis. Contemporary art.

I Pesquisadora em residência pós-doutoral (PNPD/CAPES) no Programa de Pós-graduação em Artes da Escola de Belas Artes da Universidade Federal de Minas Gerais (UFMG). Doutora em filosofia pela Universidade Federal de Minas Gerais. Mestre em Letras pela Universidade Federal do Espírito Santo. Professora colaboradora no Programa de Pós-graduação em Artes na Escola de Belas Artes da Universidade Federal de Minas Gerais, Avenida Presidente Antônio Calos, 6627 - Pampulha, Belo Horizonte - MG, 31270-901. E-mail: rizziasoares@gmail.com. ORCID: https:// orcid.org/0000-0002-8168-148X. Lattes ID: http://lattes.cnpq.br/9627420383476218. Belo Horizonte, Brasil. 
A deflagrada crise da crítica de arte tradicional e seu declínio como disciplina autônoma compõem um tema amplamente reconhecido que tem, inclusive, gerado discussões quanto à possível morte prematura da crítica de arte. A crítica de arte como meio de análise e como modo de estabelecer juízos de valor sobre as artes, reconhecendo e definindo produções artísticas como tais que, desde o século XVIII, está associada ao projeto europeu de emancipação individual e coletiva, têm subsistido de forma ineficaz. As críticas dirigidas à modernidade são responsáveis por desferir esse golpe que não liquida essa faculdade de julgar, mas garante uma sobrevivência inoperante ${ }^{1}$. Walter Benjamin já anuncia o declínio dessa capacidade, assim como, décadas depois, Arthur Danto traz o problema de estabelecer critérios estéticos para avaliação de obras de arte. Esse é o assunto que abordamos aqui mais uma vez, entretanto, o sentido dessa abordagem é observar as transformações da crítica de arte e não promovermos uma análise acerca das afirmações de seu fim.

A crítica tem integrado a produção artística de maneira cada vez mais indissociável e ativa, sobretudo nos trabalhos que partem de uma percepção atenta das relações entre território e identidade no capitalismo tardio. Portanto, se há uma necessidade de reiterar a crise da crítica de arte e seu declínio como disciplina autônoma, isso acontece aqui como forma de preparar o solo para cultivar uma atividade crítica cuja a expansão dos sentidos seja privilegiada em detrimento de ideias judicativas comuns às práticas formalistas da crítica. É para tomar essa direção que retornamos ao tema da crise.

\section{Crítica de arte em crise}

As artes contemporâneas, em suas produções, transpõem limites formais, promovendo hibridizações e inaugurando novas linguagens. Contrariando o ideal moderno de uma natureza a priori da arte, as produções contemporâneas ampliam suas possibilidades de ação no mundo mostrando uma

1 "les critiques adressées à la modernité depuis au moins deux décennies auraient en effet pous conséquence de porter un coup fatal à la critique moderne, à cette faculté de juger associée, depuis le XVIII siècle, au projet d'émancipations individuelle et collective; mais ce coup serait porté de façom inédite: il s'agirait non pas de liquier la critique, mais d'assurer sa survie sur le mode de l'inefficacité." Cf. JIMENEZ, Marc. La critique. Crise de l'art ou consensus culturel? Paris: Klincksieck. p. 11. 
abertura que as facultam serem o que quiserem ou como Moeglin Delcroix ${ }^{2}$ diz de maneira mais contundente, e indo um pouco além, é porque a arte pode ser tudo, e não qualquer coisa, que se coloca a questão do que ela deve ser. Nesse contexto, é possível ainda à crítica de arte tradicional estabelecer critérios para sua atividade e determinar com clareza qual é a sua função?

No contexto da experiência europeia, a crítica de arte surge no século XVIII como área de conhecimento quando a ideia de autonomia da arte se forma. Como discurso teórico, a crítica nasce embasada sobre os conceitos de originalidade, de intelectualização do público e do artista, contribuindo, assim, para o fortalecimento de exposições públicas, recentes coleções privadas e dos museus em formação. Tais ações eram desenvolvidas valorizando a obra de arte como um elemento autônomo. $O$ discurso sobre a arte toma instâncias mais abrangentes na segunda metade do século XVIII quando surgem a Estética Filosófica com Alexander Baumgarten e Immanuel Kant, a história da arte com Johann Joachim Winckelmann e a teoria da arte com Gotthold Ephraim Lessing. Em sua obra sobre o Laocoonte, Lessing ${ }^{3}$ desenvolve uma demarcação dos limites da pintura e da poesia qualificando as artes do espaço e as artes do tempo. Esses discursos sobre as artes, empenhados na construção de prescrições estéticas que balizem critérios valorativos das obras, são questionados logo no início do movimento das vanguardas no século XIX. Na Arte Moderna, a deflagrada crise das representações e as sucessivas transformações de linguagem artística impossibilitam à crítica uma atuação fundamentada na construção de critérios a priori para avaliação das obras. Assim, podemos observar que as relações estabelecidas pela crítica no decorrer dos diversos contextos históricos da experiência europeia das artes, e no decorrer da própria arte, deixam dúvidas quanto aos seus critérios e funções. Se, por um lado, essa incerteza produz o declínio do trabalho do crítico de arte, como escreve Walter Benjamin na década de 1920 em Rua de mão única, teorias formuladas pelos próprios artistas são cada vez mais frequentes modificando, assim, o discurso crítico. Em 1912 “O Almanaque do Cavaleiro Azul" (Reiter Blaue) é publicado por Franz Marc e Kandinsky e nele os artistas são chamados a refletir sobre suas responsabilidades com a teoria da arte moderna ressaltando que cabe ao artista ser o primeiro a

2 DELCROIX. L'inspiration philosophique de l'art contemporain. Revue d'esthétique, n. 43. Paris: Editions Jean-Paul Michel, 2003.

3 Cf. LESSING. Laocoonte ou sobre as fronteiras da pintura e da poesia. São Paulo: Iluminuras, 2011. 
se pronunciar sobre as questões artísticas ${ }^{4}$. Evidentemente, tais questões não estão encerradas no artista, mas essa demanda inaugura uma dialética entre teoria e prática artísticas que fomentam o pensamento plástico.

Essa clareza com que Benjamin percebeu o declínio da atividade da crítica de arte se deu não só pela observação do crescente questionamento dos parâmetros estéticos exercidos pelos movimentos de vanguarda, mas também pela vivência do próspero capitalismo industrial responsável por converter manifestações culturais em mercadoria. Consequentemente, a crítica, como forma de valoração do objeto, é facilmente cooptada como instrumento de mercado, por isso, afirma Benjamin "insensatos os que lamentam o declínio da crítica. Pois sua hora há muito tempo já passou. Crítica é uma questão de correto distanciamento" ${ }^{5}$. Nesse contexto, voltamos nossa atenção à tese benjaminiana acerca dos românticos alemães, na qual a crítica é pensada como um elemento constitutivo da obra de arte perdendo sua conformação unicamente textual. A crítica, compreendida então como elemento inerente à obra de arte, perde a estabilidade de seu critério de julgamento, pois seu centro de gravidade não está na avaliação da obra singular, mas está na exposição de suas relações com todas as demais obras e, finalmente, com a ideia da arte ${ }^{6}$.

Os fenômenos que provocaram o declínio da atividade crítica tradicional favoreceram o ingresso do artista na esfera crítica alterando o sentido mesmo da crítica, a qual deixa de se conformar como um discurso textual de julgamento da realização artística para se tornar reflexão da obra e motor de sua criação no desenvolvimento das poéticas artísticas.

\section{A estabilidade estética e a crítica vanguardista}

Arthur Danto em A transfiguração do lugar-comum apresenta um problema importante para a história da arte ao questionar o domínio de uma espécie de prescrição estética que esteve vinculada à produção das obras durante

\footnotetext{
4 FERREIRA. Debate crítico?!. Revista Porto Arte. p. 34.

5 BENJAMIN. Rua de mão única, p. 54.

6 BENJAMIN. O conceito de crítica de arte no romantismo alemão, p. 83.
} 
séculos. Embora tenha desenvolvido o problema de forma controversa, e por isso seja alvo de críticas cabíveis, o autor levanta questões importantes para o contexto da teoria das artes. Dessa forma, no trabalho citado acima, Danto questiona a estabilidade das produções artísticas que pré-estabeleciam a forma das obras por meio de uma generalização estética preconcebida:

[...] em períodos de estabilidade artística somos capazes de identificar obras de arte por indução e isso nos leva a crer que dispomos de uma definição [de arte], quando na verdade tudo o que temos é uma generalização extremamente circunstancial ${ }^{7}$.

Na França, essa estabilidade foi traçada do decorrer da história das chamadas belas-artes cuja unidade se estrutura, inicialmente, na separação entre desenho, pintura, escultura e arquitetura. Desde o século XVII, essas formas artísticas constituem as bases da Academia Real de Pintura e Escultura. Essa estabilidade de caráter metafísico na arte, comum à estética prescritiva de trabalhos como o Laocoonte de Lessing, apoia-se num apriorismo supra-histórico que se pretende definitivo ${ }^{8}$.

Passados alguns séculos em que a história da arte se constituiu como história estético-normativa de pretensões universais, a condição de objeto artístico como objeto estético começa a ser questionada. A partir de 1900, a tradição estética é observada em seu modo de impor limites que debilitam a arte e as vanguardas surgem questionando a restrição da arte à beleza. O Dada, movimento vanguardista que teve Marcel Duchamp como um de seus integrantes, manteve claro esse projeto de desvinculação "como expressão de revolta moral contra uma sociedade que rende culto à beleza e à arte em razão da beleza" ". A recusa a essa relação de dependência arte-belo desencadeou o problema da aplicação do conceito de obra de arte à produção vanguardista. Segundo Peter Bürger, em uma de suas teses apresentadas em Teoria da Vanguarda, a categoria de obra legitimada por certa noção de história, entra em uma crise de seus pontos fundamentais com o questionamento da instituição social da arte e o tipo de produto que ela estabelece.

7 DANTO. A transfiguração do lugar-comum. p. 109.

8 Cf. o ensaio de Gerd Bornheim sobre a influência da leitura dogmática da poética de Aristóteles, responsável por estabelecer regras à força de ignorar os contrastes óbvios entre a antiguidade e os tempos modernos, BORNHEIM. Páginas de filosofia da arte. Rio de Janeiro: Editora Uapê, 1998.

9 DANTO. El abuso de la belleza. p. 89. (tradução nossa) 
O objetivo da crítica vanguardista não foi um ataque às tendências artísticas anteriores, mas a própria arte como instituição e suas transformações a partir do desenvolvimento da sociedade burguesa. A instituição circunscreve tanto o aparelho distribuidor, que submete a obra de arte à recepção burguesa, quanto o aparelho produtor, que configura a obra de arte burguesa segundo o princípio de autonomia. Se antes os artistas eram responsáveis por transmitir valores constituídos socialmente, aos quais estavam submetidos, o estético como "forma pura" surge com o desligamento de valores heterônomos. Essa autonomia da arte, endossada pela sociedade burguesa, leva a um esteticismo desligado das questões sociais, como nos mostra a teoria da "visibilidade pura" desenvolvida pelo historiador da arte Heinich Wölfflin e endossada pelo crítico Clement Greenberg ${ }^{10}$. Mas muitos vanguardistas, ao questionar os limites da arte burguesa, investigam a forma "abrindo caminho a explorações sistemáticas e perfeitamente programadas sobre a força subversiva das formas inéditas"11. Nesse processo, eles procuravam reconduzir a arte à vida cotidiana e, consequentemente, às questões sociais, revelando os efeitos nocivos motivados pela autonomia. No esteticismo, a falta de consequência social da arte é patente. Quando a arte se torna conteúdo de si mesma, afastada da vida prática, a autonomia se deteriora em alienação.

Em síntese, sob a ótica das classificações de tradição europeia, a arte é descrita, em seu desenvolvimento histórico, por obras que se constituíram a partir de princípios fundamentais, os quais estabeleceram padrões perceptuais para produção e recepção das obras de arte durante quase dois séculos. Com as ações das vanguardas, esses sistemas de referência, dentro dos quais surgiram os vários estilos de época, são desagregados. $\mathrm{Na}$ modernidade, o declínio dessa narrativa de sustentação da arte de força hegemônica se caracterizou pela busca do novo, pela luta para romper com o academicismo, com as convenções burguesas e, claro, com os valores artísticos tradicionais. Já a arte contemporânea tem origem na mistura de linguagens, diluindo fronteiras e abrindo um campo de experimentações e inovações livres do peso da adequação a determinados padrões estéticos prévios que seriam imprescindíveis à sua produção. No entanto, é o impulso

10 Cf. FERREIRA, Glória; MELLO, Cecilia Cotrim de. (Orgs). Clement Greenberg e o debate crítico. Rio de Janeiro: Jorge Zahar, 2001

11 JIMENEZ. O que é estética?. p. 282. 
de dissolver a divisão entre arte e vida cotidiana, irrompendo no espaço público e na sociedade, que constitui o contorno maior da criação artística na passagem da arte moderna para a contemporânea.

Nesse contexto, comemora-se uma abertura da possibilidade de produção artística a países que estiveram excluídos da história da "arte universal" construída pelos historiadores europeus dentre os quais Giorgio Vasari é considerado uma espécie de precursor. No entanto, não é possível pensarmos em uma historiografia tradicional da arte sem incorrermos em fissuras, fraturas e lacunas. A "arte universal" emerge como "a quimera de uma cultura global pela qual a história da arte é desafiada como um produto da cultura europeia", afirma Hans Belting ${ }^{12}$. Reivindicar a posse da origem da história universal da arte é reivindicar o direito de ser o solo determinante do significado da experiência do conhecimento e da verdade para todos.

\section{Um desenvolvimento histórico da crítica das artes.}

O antigo árbitro da arte, amador esclarecido que se autoriza a julgar as obras, é institucionalizado e tem seu status reforçado tornando-se crítico de arte no século XVIII. Mas se aquele que exerce esse novo ofício julga seus contemporâneos, às vezes de maneira virulenta, ele não é o juiz que sentencia se um objeto deve integrar ou não o conjunto de obras de arte. A prática crítica da época consistia, sobretudo, em esclarecer o leigo, em distribuir o privilégio do bom gosto cultivado, monopolizado por poucos, a fim de favorecer um alargamento da audiência. Os meios desta mediação cultural se encontram na filosofia, já crítica a partir de Kant, bem como na Estética, recentemente fundada como disciplina. Nesse contexto, citando apenas dois grandes exemplos, Denis Diderot distingue o que the parece belo ou feio, agradável ou repugnante, fiel ou não à realidade e, mais tarde, Charles Baudelaire estrutura a crítica a partir da experiência da produção da obra de arte, entendendo sua relação histórica e defendendo critérios autônomos.

A origem da crítica também foi motivada pela percepção estética burguesa, uma nova percepção em ascensão na esfera pública. O surgimento de um

12 BELTING. O fim da história da arte: uma revisão dez anos depois. p. 18. 
cidadão que é parte integrante e construtor de uma nova ordem social se fundamenta na convicção da soberania de um indivíduo cujo acesso ao conhecimento respalda sua posição na esfera pública. Mas, na situação atual da arte, o que é realizado como crítica hoje se distingue de sua atuação na modernidade. A presença forte do mercado e sua ocupação dos espaços públicos da arte, bem como o crescimento das instituições, restringem o campo de atuação da crítica e modificam suas relações com a arte.

Massimiliano Gioni, um dos curadores responsáveis pela $55^{\mathrm{a}}$ Bienal de Veneza e membro da equipe curatorial do New Museum em Nova lorque, afirma que "arte é o que a cultura decide ser arte, arte é muita coisa, e arte é também confiança nos critérios de alguém que diz que algo é arte"13. A arte existe além do circuito institucional, mas é a partir das instâncias institucionais que ela consolida o seu valor. Esse processo de valoração, que não exclui o preço, é integrado pela reflexão crítica. A produção, as instituições e o mercado compõem as demais instâncias. Quando há um equilíbrio na inter-relação dessas diferentes instâncias que compõem o sistema das artes, a produção é fomentada e fortalecida. Porém, em sistemas menos consolidados em que há uma ausência da reflexão crítica e fragilidade institucional, o mercado predomina na definição dos valores artísticos. A predominância do mercado como maior instância de valoração limita a experimentação e restringe o impulso de resistência na arte. Essa é uma das consequências do enfraquecimento da crítica. Nesse ambiente, a crítica sobrevive longe do espaço público, em ensaios publicados em catálogos de exposições, subordinados aos interesses das instituições, que, em alguma medida, estão ligadas aos interesses mercadológicos e empresariais. Essa crítica, segundo Sônia Salzstein, demonstra pouco interesse em confrontar trabalhos contemporâneos com referências anteriores na história da arte, com a finalidade de "revelar uma capacidade interpretativa mais generosa e algum esforço de síntese"14. Dessa forma, a crítica atual não se interessa por construir uma reflexão em longo prazo, mas está a serviço da consequente superficialidade que é produto da racionalidade administrativa e econômica.

Com o agenciamento da função do crítico pelo mercado, a crítica inaugura novas relações com a arte se misturando cada vez mais com a produção

13 QUEMIN (Org.). O valor da obra de arte.p. 89.

14 SALZSTEIN. Transformações na esfera da crítica. In: FERREIRA. Crítica de arte no Brasil. p. 232. 
artística, "assimilando, como seu, interesses e motivações que eram só da produção, buscando apresentar-se como uma modalidade própria da arte"15. Dessa maneira, crítica e produção artística estão amalgamadas na contemporaneidade e sua prática possibilita a construção de um caminho que garanta ao artista uma consciência emancipada em relação ao sistema das artes.

\section{A crítica poética}

No contexto contemporâneo, é crescente a atuação de artistas em posições diversas do que poderíamos entender como produtor de obras de arte. Ao borrar os limites entre o que pode ou não ser um trabalho de arte, a função do artista também perde a rigidez dos limites "revelando-se mais como um trânsito, um certo deslocamento através das coisas combinado com a produção de um espaço particular de problemas"16. Essa ampliação da atuação - que pode sobrepor áreas como arte e ciência ou arte e ciência e filosofia - não dificulta a construção de um território próprio do artista e suas realizações e também afetam a atividade tradicional da crítica de arte.

A crítica é uma atividade filosófica evidenciada por Immanuel Kant e, segundo Lisette Lagnado,

[...] parece impensável se dizer crítico sem o domínio de conceitos básicos enunciados por Walter Benjamin (1892-1940). Afinal, a dicotomia entre forma e conteúdo não está superada em Greenberg, mas foi lindamente elaborada em Benjamin em "O autor como produtor", de 1934. ${ }^{17}$

Apesar disso, o arcabouço filosófico tem o hábito de apenas tangenciar as questões artísticas essenciais. Ao tomar as obras de arte como exemplos para seu competente desenvolvimento argumentativo, ou propor um discurso sobre a arte distante da produção artística efetiva, o pensamento filosófico tem dificuldades em compreender a arte como um campo produtor de conhecimento e, portanto, capaz de engendrar reflexão crítica no interior de seus

15 SALZSTEIN. Transformações na esfera da crítica. In: FERREIRA. Crítica de arte no Brasil. p. 232

16 BASBAUM. O artista como curador. In: FERREIRA. Crítica de arte no Brasil. p. 235.

17 LAGNADO. As tarefas do curador. Marcelina - Revista do Mestrado em Artes Visuais da Faculdade Santa Marcelina. p. 9. 
processos. É o que Arthur Danto também reafirma em O descredenciamento filosófico da arte ao argumentar que o tratamento dado a arte pela filosofia no decorrer da história empenhou sistematicamente uma neutralização da arte a qual é "removida, por um lado, do domínio do uso e, por outro lado, do mundo de necessidades e interesses" ${ }^{18}$.

Uma das exceções a essa relação que a filosofia estabeleceu com as artes é realizada por Walter Benjamin. Filósofo e crítico, Benjamin repercute um conceito de crítica de arte que se define menos como o julgamento da obra que como método de seu acabamento ${ }^{19}$. Além de um conceito, a crítica benjaminiana é uma postura prática diante da obra que estimula uma crítica poética ${ }^{20}$ cuja atuação exporá novamente a exposição, desejará formar ainda uma vez o já formado, irá completar a obra, rejuvenescê-la, configurá-la novamente ${ }^{21}$. Tal configuração não se apoia sobre uma legislação estética e, portanto, questiona a atitude contemplativa comum ao modo tradicional de recepção da arte formatado na ascensão da burguesia. Deste modo, o observador passivo vai dando lugar ao observador ativo, cujo trabalho receptivo perfaz o objeto ou ação artística. Assim, a realização artística, compreendida como projeto ou obra inacabada, completa-se na recepção pública por meio da reflexão crítica. Para isso Benjamin propõe uma reconfiguração do conceito de crítica e, dessa forma, um reposicionamento do crítico diante da produção artística.

A ideia de uma crítica de arte poética não tem início com Benjamin. Ela se constitui como uma categoria de crítica de arte que precede os trabalhos do filósofo e tem Charles Baudelaire como um de seus representantes. O que encontramos em Benjamin é uma articulação teórico-filosófica da crítica poética a partir dos românticos alemães, como em Immanuel Kant encontramos o fundamento da crítica judicativa. O problema da crise da crítica de arte, sobretudo da crítica formalista, e seu possível declínio prematuro como gênero literário, também não é um assunto recente e têm recebido

18 DANTO. O descredenciamento filosófico da arte. p. 43.

19 BENJAMIN. O conceito de crítica de arte no romantismo alemão. p. 75.

20 O uso desse termo aqui está diretamente associado à sua origem grega poíese, cujo sentido está relacionado à criação, ou seja, não se trata de uma crítica poética enquanto forma literária própria da poesia.

21 Op. cit. p. 75. 
bastante atenção. Guilio Carlo Argan em seu livro Arte e crítica de arte inicia o último capítulo intitulado "A crise da crítica e a crise da arte" declarando "a renúncia e incapacidade da crítica de continuar a afirmar-se como juízo correspondente à orientação ou até mesmo aos enunciados 'críticos' das correntes artísticas mais recentes" 22 . Segundo o autor, isso se daria porque tais correntes artísticas além recusarem uma submissão ao juízo também rejeitam "produzir o que quer que seja julgável"23. Ainda segundo Argan, se a crítica age como mediação entre a arte e o público, orientando escolhas e interesses e, consequentemente, apoiando uma ou outra corrente, intervindo no seu contraste dialético e político, uma crítica em crise se manifesta como dificuldade de comunicação entre arte e sociedade ${ }^{24}$. Também Hal Foster afirma o enfraquecimento da crítica como valor estético ${ }^{25}$. E em What Happened to art criticism? de James Elkins lemos que "a crítica de arte [atualmente] é massivamente produzida e massivamente ignorada" ${ }^{26}$. Nesse pequeno livro o autor mapeia, de forma bem objetiva, as mudanças sofridas pela crítica, ordenando a prática da crítica de arte contemporânea em sete categorias: ensaio para catálogo de exposições, tratado acadêmico, crítica cultural, discurso conservador ${ }^{27}$, ensaio filosófico, crítica de arte descritiva e crítica de arte poética. Não é o foco da discussão desenvolvida aqui examinar cada uma dessas categorias, mas vamos nos deter em alguns comentários acerca da crítica de arte poética, última categoria traçada por Elkins.

Uma hidra de sete cabeças, é assim que a crítica é representada em What Happened to art criticism? e, dentre essas cabeças, a crítica poética é a mais proeminente. Esse destaque deriva da opinião popular sobre o propósito da crítica de arte, o qual seria criar um texto com valor literário ${ }^{28}$. Nesse caso, espera-se de um trabalho crítico que ele descreva a obra de arte contextualizando-a historicamente em um texto com boa qualidade literária. Grosso

22 ARGAN. Arte e crítica de arte. p. 159.

23 Ibidem.

24 Ibid.p. 23.

25 Cf. FOSTER. O retorno do real.

26 ELKINS. What happened to art criticism? p. 4.

27 conservative harangue é o termo usado por Elkins.

28 ELKINS. What happened to art criticism?. p. 49. 
modo, a classificação de crítica poética oferecida por Elkins resume-se a um texto com alcance literário que mobilize o aparato da crítica tradicional, ou seja, os critérios de julgamento do trabalho artístico e a sua contextualização nas correntes artísticas, as quais, é importante ressaltar, raramente estão fundamentadas em outra experiência das artes para além da experiência euro-estadunidense. Assim, o conceito de crítica poética tratado pelo autor ainda permanece próximo de uma prática judicativa, mesmo que guarde algumas diferenças.

Mas se o ponto central que impulsiona a discussão aqui desenvolvida reside em refletir acerca das transformações da crítica, integra essa discussão pensar como a crítica permeia as atividades artísticas e como as atividades artísticas permeiam o trabalho crítico na produção artística contemporânea. Para tanto, é necessário voltarmos nossa atenção para os limites entre artista e produção crítica, pois, se tais limites são borrados, o mesmo acontece entre crítica de arte e artista.

\section{Limites entre arte e crítica}

Há uma dimensão reflexiva na própria produção artística que faz com ela seja motora de sua própria crítica. Frederico Morais, autor que também reconhece a crise da crítica de arte afirmando ainda que os críticos "se ressentem da falta de critérios de julgamento" ${ }^{29}$, compreende essa forma motriz da arte em sua ideia de crítica aberta.

A crítica aberta, portanto, é aquela que não busca na obra de arte apenas um sentido, mas a sua multiplicidade, que não pretende submeter a obra a um controle rígido e mesquinho. "O crítico será tanto mais criador [...] quanto mais colhido ele está pela obra". A nova crítica, portanto, não será judicativa. ${ }^{30}$

A crítica aberta, a qual é uma forma de crítica poética, não se restringe ao texto. Ela pode ser um trabalho de arte que surge como crítica a outro 
trabalho de arte. Quando em sua dimensão textual, a crítica se estabelece sobre outra forma de relacionamento entre o texto e as artes, uma forma na qual a escrita desempenha um papel na expansão dos sentidos. Para tal desempenho, o jogo tradicional entre trabalho de arte e comentário crítico, a partir do qual a crítica textual se estrutura em uma premissa judicativa ou didática, é abandonado. Outro jogo, então, é requerido, segundo o qual a norma dos textos para abordar arte não parta de uma posição reativa frente as produções artísticas, mas ocupe uma posição inventiva. Ou seja, uma crítica poética não se movimenta exclusivamente a partir da reação ao trabalho dos artistas. Uma crítica poética amplifica a arte e os sentidos enquanto transpõe os limites formais entre análise e invenção.

O que realmente conta é a habilidade do texto em subverter o padrão de tempo tradicional (a cadeia passado-presente-futuro), interatuando com os trabalhos de modo a enfatizar sua atualidade e pertencimento ao presente: a combinação de texto prospectivo e trabalho de arte fabrica um agregado conceitual-sensorial que de fato opera como produção de real. ${ }^{31}$

Ricardo Basbaum faz ecoar O conceito de crítica de arte no romantismo alemão no qual Benjamin também afirma que a arte é verdade, não ficção ${ }^{32}$. Se há uma crítica de arte apoiada em parâmetros tradicionais que responde ao Sistema das Artes tornando-se responsável por converter a produção artística em objeto de um corpus profissionalizado de discursos, a crítica poética compreende um campo sensorial inseparável da rede conceitual e tal prática crítica se configura muito "menos como o julgamento de uma obra do que o método de seu acabamento"33. Nessa perspectiva, a crítica é uma operação que aprimora, enriquece a produção das artes interrompendo uma regra de escrita sobre arte em que os artistas produzem e os críticos comentam.

Ao reproduzir infinitamente essa estrutura, uma certa hierarquia é produzida: artistas na base, como produtores de imagens; críticos e curadores (e

31 BASBAUM. Manual do artista-etc. p. 43.

32 BENJAMIN. O conceito de crítica de arte no romantismo alemão. p. 76.

33 Ibid. p. 75. 
galeristas) no topo, como aqueles responsáveis por organizar a discussão sobre o sentido dos trabalhos. ${ }^{34}$

E ainda há aquela dimensão da crítica poética que não está ligada ao texto. Com a contingência em estabelecer claros limites entre artista e crítico, é possível à crítica assumir outras formas e, consequentemente, outros espaços. Na década de 1970 Frederico Morais explora essa dimensão poética da crítica para além da forma textual em sua exposição A Nova Crítica. Nessa exposição, a primeira de uma série, o crítico também é artista e seus trabalhos têm como força motriz a crítica suscitada pela produção de outros artistas.

Cerca de duas décadas depois em que essa dimensão da crítica começa a ser explorada por Frederico Morais, a retomada da arte site-specific, na qual o relacionamento entre arte e lugar (site) é redefinido e a compreensão de espaço como algo físico vai perdendo lastro, também se torna um dos meios em que a crítica se faz presente como um dos operadores poéticos da produção artística. Artistas como Jimmie Durham, Maria Thereza Alves e Mark Dion, para citar alguns poucos nomes, trazem a crítica como um dos elementos formais inerentes aos seus trabalhos. Essa dimensão poética da crítica tem integrado a produção artística contemporânea e tencionando a experiência das artes provocando, para além da sensibilidade estética, a sensibilidade crítica do espectador.

\section{Referências}

ARGAN, Giulio Carlo. Arte e crítica de arte. Lisboa: Estampa Editorial, 1988.

BASBAUM, Ricardo. Manual do artista-etc. Rio de Janeiro: Beco do Azougue, 2013.

BASBAUM, Ricardo. O artista como curador. In: FERREIRA, Glória. Crítica de arte no Brasil. Rio de Janeiro: FUNARTE, 2006. 
BELTING, Hans. O fim da história da arte: uma revisão dez anos depois. São Paulo: Cosac Naify, 2012.

BENJAMIN, Walter. O conceito de crítica de arte no romantismo alemão. São Paulo: Iluminuras, 2002.

BENJAMIN, Walter. Rua de mão-única. Obras escolhidas. vol. 2. São Paulo: Brasiliense, 1995.

BÜRGER, Peter. Teoria da vanguarda. Trad. José Pedro Antunes. São Paulo: Cosac Naify, 2012.

DANTO, Arthur C. A transfiguração do lugar-comum. São Paulo: Cosac Naify, 2005a.

DANTO, Arthur C. O descredenciamento filosófico da arte. Trad. Rodrigo Duarte. Belo Horizonte: Autêntica, 2014.

DANTO, Arthur C.. El abuso de la belleza. Barcelona: Edicione Paidós, 2005b.

ELTKINS, James. What happened to art criticism? Prickly Paradigm Press: Chicago, 2003.

FERREIRA, Glória. Debate crítico?!. Revista Porto Arte: Porto Alegre, v. 16, No 27, p. 31-41, Novembro/2009.

FERREIRA, Glória; MELLO, Cecilia Cotrim de. (Orgs). Clement Greenberg e o debate crítico. Rio de Janeiro: Jorge Zahar, 2001.

JIMENEZ, Marc. O que é estética? Trad. Fulvia M. L. Moretto. São Leopoldo: UNISINOS, 1999.

LAGNADO, Lisette. As tarefas do curador. In: Marcelina. Revista do Mestrado em Artes Visuais da Faculdade Santa Marcelina. Ano 1, v. 1. São Paulo: Fasm, 2008.

LESSING, G. E. Laocoonte ou sobre as fronteiras da pintura e da poesia. Trad. Márcio Seligmann-Silva. São Paulo: Iluminuras, 2011.

MOEGLIN-DELCROIX, A. L'inspiration philosophique de l'art contemporain. Revue d'esthétique, n. 43. Paris: Editions Jean-Paul Michel, 2003. 
MORAIS, Frederico. Artes plásticas: a crise da hora atual. Rio de Janeiro: Paz e Terra: 1975.

QUEMIN, Alan (Org.). O valor da obra de arte. São Paulo: Metalivros, 2014.

SALZSTEIN, Sônia. Transformações na esfera da crítica. In: FERREIRA, Glória. Crítica de arte no Brasil. Rio de Janeiro: FUNARTE, 2006. 